\title{
Surgical outcomes of elderly patients with cervical spondylotic myelopathy: a meta-analysis of studies reporting on 2868 patients
}

\author{
Karthik Madhavan, MD, Lee Onn Chieng, BS, Hanyao Foong, BS, and Michael Y. Wang, MD \\ Department of Neurological Surgery, University of Miami, Florida
}

OBJECTIVE Cervical spondylotic myelopathy usually presents in the 5 th decade of life or later but can also present earlier in patients with congenital spinal stenosis. As life expectancy continues to increase in the United States, the preconceived reluctance toward operating on the elderly population based on older publications must be rethought. It is a known fact that outcomes in the elderly cannot be as robust as those in the younger population. There are no publications with detailed meta-analyses to determine an acceptable level of outcome in this population. In this review, the authors compare elderly patients older than 75 years to a nonelderly population, and they discuss some of the relevant strategies to minimize complications.

METHODS In accordance with PRISMA (Preferred Reporting Items for Systematic Reviews and Meta-Analyses) guidelines, the authors performed a PubMed database search to identify English-language literature published between 1995 and 2015. Combinations of the following phrases that describe the age group ("elderly," "non-elderly," "old," "age") and the disease of interest as well as management ("surgical outcome," "surgery," "cervical spondylotic myelopathy," "cervical degenerative myelopathy") were constructed when searching for relevant articles. Two reviewers independently assessed the outcomes, and any disagreement was discussed with the first author until it was resolved. A random-effects model was applied to assess pooled data due to high heterogeneity between studies. The mean difference (MD) and odds ratio were calculated for continuous and dichromatic parameters, respectively.

RESULTS Eighteen studies comprising elderly $(n=1169)$ and nonelderly $(n=1699)$ patients who received surgical treatment for cervical spondylotic myelopathy were included in this meta-analysis. Of these studies, 5 were prospective and 13 were retrospective. Intraoperatively, both groups required a similar amount of operation time $(p=0.35)$. The elderly group had lower Japanese Orthopaedic Association (JOA) scores (MD -1.36, $95 \% \mathrm{Cl}-1.62$ to $-1.09 ; \mathrm{p}<0.00001$ ) to begin with compared with the nonelderly group. The nonelderly group also had a higher postoperative JOA score (MD $-1.11,95 \% \mathrm{Cl}-1.44$ to $-0.79 ; p<0.00001$ ), therefore demonstrating a higher recovery rate from surgeries (MD -11.98 , $95 \% \mathrm{Cl}-16.16$ to $-7.79 ; p<0.00001)$. The length of stay (MD 4.14, 95\% Cl 3.54-4.73; $p<0.00001$ ) was slightly longer in the elderly group. In terms of radiological outcomes, the elderly group had a smaller postoperative Cobb angle but a greater increase in spinal canal diameter compared with the nonelderly group. The complication rates were not significant.

CONCLUSIONS Cervical myelopathy is a disease of the elderly, and age is an independent factor for recovery from surgery. Postoperative and long-term outcomes have been remarkable in terms of improvement in mobility and independence requiring reduced nursing care. There is definitely a higher potential risk while operating on the elderly population, but no significant difference in the incidence of postoperative complications was noted. Withholding surgery from the elderly population can lead to increased morbidity due to rapid progression of symptoms in addition to deconditioning from lack of mobility and independence. Reduction in operative time under anesthesia, lower blood loss, and perioperative fluid management have been shown to minimize the complication rate. The authors request that neurosurgeons weigh the potential benefit against the risks for every patient before withholding surgery from elderly patients.

http://thejns.org/doi/abs/10.3171/2016.3.FOCUS1657

KEY WORDS elderly population; cervical decompression; complication; ERAS; enhanced recovery after surgery; meta-analysis 
$\mathrm{D}$ EGENERATION of the cervical spine is a part of the natural process of aging, with $30 \%$ of the population showing degeneration in the 4th decade and $90 \%$ by the 7 th decade. ${ }^{13,14,18,44}$ Due to variable population demography, symptoms occur at various degrees of stenosis, and radiological scans do not correlate with symptom occurrence. ${ }^{10}$ As age progresses, stenosis continually progresses and most patients are symptomatic at an older age ${ }^{6,30,45,46,52}$ Decompression of the spinal cord for cervical myelopathy has shown excellent results in all age groups of the population, including the group with congenital spinal stenosis. ${ }^{2}$

On the other hand, there is a significant amount of reluctance among surgeons to perform surgery in the elderly population, given that age is an independent factor for increased morbidity with additional comorbid medical conditions. Life expectancy in the United States has been steadily increasing, with the elderly population expected to reach nearly 45 million by $2050 .^{35}$ Cervical myelopathy is debilitating, and the patient can soon become deconditioned due to the lack of activities. ${ }^{15,49}$ The goal of this meta-analysis was to pool the data from various publications to study the complication rates of patients older than 75 years and the nonelderly population and also to discuss some of the relevant strategies to limit and overcome complications.

\section{Methods}

\section{Study Selection}

Combinations of key words that describe age groups ("elderly," "non-elderly," "old," "age") and disease of interest as well as management ("surgical outcome," "surgery," "cervical spondylotic myelopathy," "cervical degenerative myelopathy") were used when searching for relevant articles. Two reviewers (L.O.C. and H.F.) independently performed each step of the study selection process. Additional articles were located by cross-referencing articles encountered initially through the PubMed searches. Inclusion criteria required a minimum of 40 patients per study and a report of appropriate outcome data that allowed pooled data analysis. We included case series, retrospective studies, prospective reports, and clinical trials that reported cases of degenerative etiology of cervical myelopathy in our study. Other etiologies such as neoplastic or trauma were not included. Reviews, case reports, cadaveric studies, editorials, and commentaries were excluded.

\section{Data Extraction}

After the initial screening using the previously mentioned criteria, the 2 reviewers independently assessed the quality and methodology of each study with the method recommended by the Grading of Recommendations Assessment, Development and Evaluation (GRADE) ${ }^{47}$ The interpretation of an overall strength of "high" means that further research is very unlikely to change our confidence in the estimate of effect as it lies close to that of the true effect. "Moderate" is interpreted as further research is likely to have an important impact on our confidence in the estimate of effect and may change the estimate. A grade of "low" means that further research is very likely to have an important impact on our confidence in the estimate of effect and is likely to change the estimate, whereas "very low" means that any estimate of effect is very uncertain.

The articles were further analyzed based on patient population, country, type of surgical intervention, associated outcomes, length of follow-up, and complications. If there was disagreement regarding the potential relevance of each study, both reviewers discussed the differences with each other until a consensus was reached.

\section{Statistical Analysis}

To analyze efficacy of surgical intervention, clinical outcome parameters such as the Japanese Orthopaedic Association (JOA) score and recovery rate (\%) were used to calculate mean differences (MDs) in both elderly and nonelderly groups utilizing forest plotting. The JOA score evaluates patients based on functions of the upper extremity (4 points) and lower extremity (4 points); sensory examination results of the upper extremity, lower extremity, and trunk ( 2 each); and bladder function ( 3 points). The higher the JOA score, the better the functional status of the patient during the time of assessment. A healthy patient would get a score of 17 points. Some of these studies also attempted to use recovery rate (\%) derived from the Hirabayashi formula to further demonstrate efficacy of treatment: (postoperative JOA score - preoperative JOA score $) \times 100 /(17$ - preoperative JOA score $){ }^{6}$ Radiological outcome parameters of interest such as cervical Cobb angle and spinal canal diameter before and after surgery were also analyzed. The cervical Cobb angle represents the angle between 2 crossed perpendicular lines that are extended parallel to the inferior endplates of C-2 and C-7 on a lateral radiograph of the cervical spine. Spinal canal diameter is measured on an axial MR image of the affected cervical vertebrae. In our analysis, we estimated MD with a 95\% confidence interval. Random-effects models were employed due to high heterogeneity of $>70 \%$ in most analyses. Odd ratios with $95 \%$ confidence intervals were also calculated for dichromatic parameters, which included complication rates. Publication biases were also assessed by constructing a funnel plot and Egger test. A p value of $<0.05$ was considered statistically significant. All analyses were performed using RevMan version 5.0.

\section{Results \\ Search Results}

With compliance to the Preferred Reporting Items for Systematic Reviews and Meta-Analyses (PRISMA) guidelines, we performed a PubMed database search to identify English-language literature published between 1995 and 2015. The initial search returned 731 studies. After extensive screening, 18 full-text articles that met previously described criteria were included. Of these studies, 5 were prospective and 13 were retrospective in terms of study design. A detailed flowchart of the search procedure is depicted in Fig. 1.

\section{Baseline Characteristic}

The characteristics of 18 studies that were included in this meta-analysis are summarized in Table 1. These 


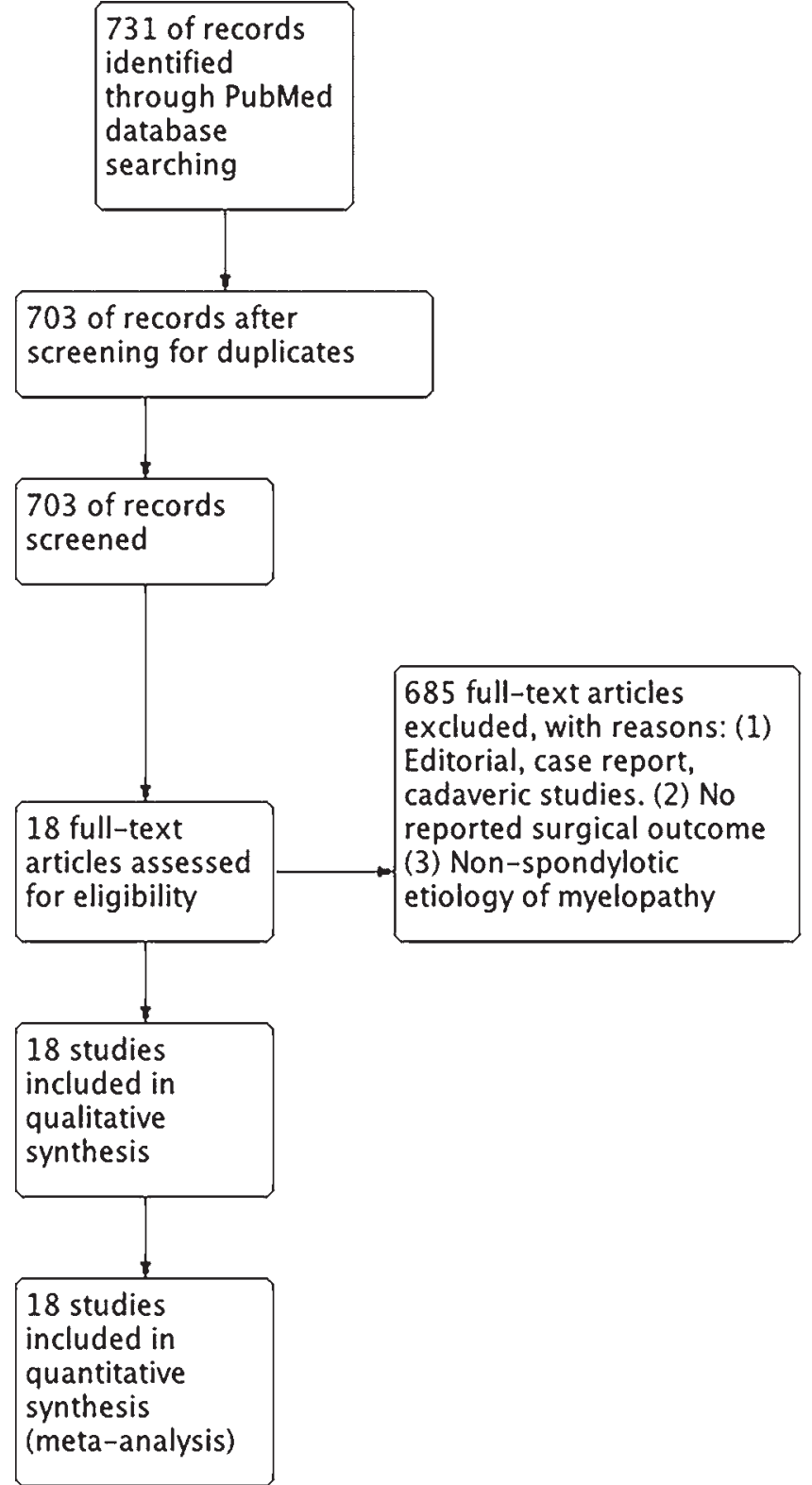

FIG. 1. PRISMA flowchart detailing the search strategy for study inclusion.

studies comprised a total of 2868 patients (1169 and 1699 patients were stratified to elderly and nonelderly groups, respectively). Eight studies used 75 years old as the cutoff to define elderly age, while the remaining studies used 65 or 70 years old as the minimum thresholds. Table 2 demonstrates baseline characteristics of each group. The average age of the elderly group was $74.1 \pm 5.7$ years, while the average age of the nonelderly group was $54.6 \pm 10.0$. A posterior approach for surgical decompression was more popular in the nonelderly group (85.3\%), whereas an anterior approach was most commonly followed (72.6\%) in the elderly group. In the elderly group $47 \%$ of the patients were female; $55 \%$ of patients were found to have diabetes prior to surgery in the elderly group compared with $45 \%$ in the nonelderly group.

\section{Intraoperative Parameters}

Six studies comprising 780 elderly patients and 1244 nonelderly patients provided information regarding operative time (Fig. 2). Although not statistically significant, the elderly group required less operation time (MD -6.05 minutes, $95 \% \mathrm{CI}-18.65$ to $6.54, \mathrm{p}=0.35)$. However, there was significant heterogeneity between studies $\left(\mathrm{I}^{2}=90 \%, \mathrm{p}\right.$ $<0.00001)$. Interestingly, the elderly group demonstrated a significant decrease in intraoperative blood loss (MD $-12.83 \mathrm{ml}, 95 \% \mathrm{CI}-24.54$ to $-1.11 ; \mathrm{p}=0.03$ ) compared with the nonelderly counterpart (Fig. 3).

\section{Clinical and Radiological Outcomes}

Fourteen studies, with 1042 elderly patients and 1615 nonelderly patients, used the JOA score to evaluate functional status before and after surgery. The elderly group had lower JOA scores (MD -1.36, 95\% CI -1.62 to -1.09 ; $\mathrm{p}<0.00001$ ) to begin with (Fig. 4) as compared with the nonelderly group and therefore lower postoperative JOA scores (Fig. 5, MD -1.11, 95\% CI -1.39 to -0.84 ; p < 0.00001). Not surprisingly, these elderly patients had lower recovery rates (Fig. 6, MD $-11.98 \%, 95 \% \mathrm{CI}-16.16 \%$ to $-7.79 \% ; \mathrm{p}<0.00001)$. They also had slightly longer length of stay in the hospital (Fig. 7, MD 3.93 days, 95\% CI 3.054.82 days; $\mathrm{p}<0.00001)$.

Few studies reported radiological parameters, which included cervical Cobb angle and spinal canal diameter before and after surgery for comparison. The pooled average preoperative Cobb angle was $11.5^{\circ} \pm 10.8^{\circ}$ in the elderly group compared with $14.2^{\circ} \pm 9.8^{\circ}$ in the nonelderly group (Fig. 8). In comparison, the elderly group had a smaller preoperative $\mathrm{Cobb}$ angle $\left(\mathrm{MD}-3.20^{\circ}, 95 \% \mathrm{CI}\right.$ -5.53 to $-0.88 ; \mathrm{p}<0.007)$. On the other hand, the pooled average postoperative Cobb angle was $14.3^{\circ} \pm 10.6^{\circ}$ in the elderly group compared with $15.8^{\circ} \pm 11.7^{\circ}$ in the nonelderly group (Fig. 9). This observed difference was shown to be significant $(\mathrm{MD}-2.47,95 \% \mathrm{CI}-4.27$ to $-0.68, \mathrm{p}=$ $0.007)$. Meanwhile, the pooled mean postoperative spinal canal diameter was $19.3 \mathrm{~mm} \pm 2.1 \mathrm{~mm}$ in the elderly group compared with $15.7 \mathrm{~mm} \pm 3.4 \mathrm{~mm}$ in the nonelderly. The elderly group was observed to have greater postoperative spinal canal diameter (Fig. 10, MD $2.32 \mathrm{~mm}, 95 \% \mathrm{CI}$ -1.60 to $6.24 \mathrm{~mm} ; \mathrm{p}<0.25)$.

\section{Complications and Adverse Events}

C-5 palsy, CSF leak, pneumonia, and delirium were the most common reported complications after surgery. However, the incidence of C-5 palsy seen in 5 studies was evenly distributed among elderly and nonelderly groups, with no evidence of statistical significance (Fig. 11, OR 1,95\% CI $0.38-2.67, \mathrm{p}=1.0$ ). Although most studies demonstrated a higher incidence of CSF leak in elderly patients as found in 4 studies (Fig. 12), statistical significance was not reached (OR 2.62, 95\% CI 0.67-10.27; p = 0.17). Similarly, the elderly also had a higher but not significant, incidence of pneumonia (Fig. 13, OR 3.94, 95\% CI 0.77-20.08; p = $0.10)$. Lastly, delirium was the only complication found to be significantly higher in the elderly group (Fig. 14, OR $6.69,95 \%$ CI 1.1-40.6, $\mathrm{p}=0.04$ ) with pooled results from 3 studies. 
TABLE 1. Baseline characteristics of included studies

\begin{tabular}{|c|c|c|c|c|c|c|}
\hline Authors \& Year & $\begin{array}{l}\text { Study } \\
\text { Design }\end{array}$ & Country & $\begin{array}{l}\text { No. of } \\
\text { Pts }\end{array}$ & Definition of Elderly & Surgical Technique(s) & $\begin{array}{l}\text { Mean Follow-Up in } \\
\text { Mos (range) }\end{array}$ \\
\hline $\begin{array}{l}\text { Nakashima et } \\
\text { al., } 2015\end{array}$ & Prospective & $\begin{array}{l}\text { Interna- } \\
\text { tional }\end{array}$ & 479 & $\begin{array}{l}\text { Elderly } \geq 65 \text { yrs }(n=119) ; \text { nonelderly }<65 \text { yrs } \\
\qquad(n=360)\end{array}$ & $\begin{array}{l}\text { ACDF, discectomy/corpectomy } \\
\text { w/ or w/o fusion, laminoplasty, } \\
\text { laminectomy w/ or w/o fusion }\end{array}$ & 24 \\
\hline $\begin{array}{l}\text { Chen et al., } \\
2015\end{array}$ & Retro & China & 136 & $\begin{array}{l}\text { Elderly } \geq 70 \text { yrs }(n=58) ; \text { nonelderly }<70 \text { yrs } \\
\quad(n=78)\end{array}$ & $\begin{array}{l}\text { ACDF, posterior laminectomy + } \\
\text { fixation }\end{array}$ & $39.6(9-76)$ \\
\hline $\begin{array}{l}\text { Maeno et al., } \\
2015\end{array}$ & Prospective & Japan & 100 & $\begin{array}{l}\text { Group 50s }(n=21) ; \text { Group 60s }(n=32) \\
\quad \text { Groups } 70 s(n=37) ; \text { Group 80s }(n=10)\end{array}$ & Laminoplasty & 78 \\
\hline $\begin{array}{l}\text { Machino et al., } \\
2015\end{array}$ & Prospective & Japan & 505 & $\begin{array}{l}\text { Old-old } \geq 75 \text { yrs }(n=118) ; \text { young-old } 65-74 \\
\quad \text { yrs }(n=186) ; \text { nonelderly <65 yrs }(n=201)\end{array}$ & Laminoplasty & 27.2 \\
\hline Son et al., 2014 & Retro & Korea & 62 & $\begin{array}{l}\text { Elderly } \geq 65 \text { yrs }(n=28) ; \text { nonelderly < } 65 \text { yrs } \\
\quad(n=34)\end{array}$ & Laminoplasty & NR \\
\hline $\begin{array}{l}\text { Kanchiku et al., } \\
2014\end{array}$ & Retro & Japan & 43 & Elderly $\geq 75$ yrs $(n=43)$ & ACDF, laminoplasty & 25 \\
\hline $\begin{array}{l}\text { Yoshida et al., } \\
2013\end{array}$ & Prospective & Japan & 369 & $\begin{array}{l}\text { Elderly } \geq 75 \text { yrs }(n=76) \text {; nonelderly }<75 \text { yrs } \\
\quad(n=293)\end{array}$ & Laminoplasty & 54 \\
\hline $\begin{array}{l}\text { Machino et al., } \\
2012\end{array}$ & Prospective & Japan & 520 & $\begin{array}{l}\text { Old-old } \geq 75 \text { yrs }(n=90) ; \text { young-old } 65-74 \\
\text { yrs }(n=143) ; \text { nonelderly <65 yrs }(n=287)\end{array}$ & Laminoplasty & $33.3 \pm 15.7$ \\
\hline $\begin{array}{l}\text { Nagashima et } \\
\text { al., } 2011\end{array}$ & Retro & Japan & 113 & $\begin{array}{l}\text { Group 1, 36-45 yrs ( } n=12) ; \text { Group 2, } \\
\quad 46-55 \text { yrs }(n=22) ; \text { Group } 3,56-65 \text { yrs ( } \\
\quad=31) ; \text { Group } 4,76-85 \text { yrs }(n=16)\end{array}$ & $\begin{array}{l}\text { ACDF, laminoplasty, laminec- } \\
\text { tomy }\end{array}$ & $>6$ mos \\
\hline Lu et al., 2008 & Retro & China & 51 & $\begin{array}{l}\text { Elderly } \geq 70 \text { yrs }(n=20) \text {; nonelderly }<69 \text { yrs } \\
\quad(n=31)\end{array}$ & $\begin{array}{l}\text { Anterior corpectomy+fusion+ } \\
\text { fixation }\end{array}$ & $35.3(24-55)$ \\
\hline $\begin{array}{l}\text { Ishii et al., } \\
2008\end{array}$ & Retro & Japan & 56 & Elderly $75-86$ yrs $(n=20)$ & Laminoplasty & $42(2.4-103.2)$ \\
\hline $\begin{array}{l}\text { Holly et al., } \\
2008\end{array}$ & Retro & US & 70 & $\begin{array}{l}\text { Elderly } 75-85 \text { yrs }(n=36) ; \text { nonelderly } \\
\quad 30-64 \text { yrs }(n=34)\end{array}$ & $\begin{array}{l}\text { ACDF, laminoplasty, } \\
\text { laminectomy+fusion }\end{array}$ & $24(12-48)$ \\
\hline $\begin{array}{l}\text { Yamazaki et } \\
\text { al., } 2003\end{array}$ & Retro & Japan & 64 & $\begin{array}{l}\text { Elderly } \geq 65 \text { yrs }(n=35) \text {; nonelderly }<65 \text { yrs } \\
\qquad(n=29)\end{array}$ & Laminoplasty & 40 \\
\hline $\begin{array}{l}\text { Kawaguchi et } \\
\text { al., } 2003\end{array}$ & Retro & Japan & 89 & $\begin{array}{l}\text { Elderly } \geq 70 \text { yrs }(n=20) \text {; nonelderly }<69 \text { yrs } \\
\quad(n=69)\end{array}$ & Laminoplasty & $\begin{array}{l}\text { Elderly } 39.6(12- \\
168) \text {; nonelderly, } \\
90(12-204)\end{array}$ \\
\hline $\begin{array}{l}\text { Handa et al., } \\
2002\end{array}$ & Retro & Japan & 61 & $\begin{array}{l}\text { Elderly } \geq 70 \text { yrs }(n=22) ; \text { nonelderly }<69 \text { yrs } \\
\quad(n=39)\end{array}$ & Laminoplasty & \\
\hline $\begin{array}{l}\text { Tanaka et al., } \\
1999\end{array}$ & Retro & Japan & 47 & $64-75$ yrs $(n=13) ; 76-85$ yrs $(n=34)$ & Laminoplasty & \\
\hline $\begin{array}{l}\text { Matsuda et al., } \\
1999\end{array}$ & Retro & Japan & 41 & $75-81$ yrs $(n=17) ; 20-63$ yrs $(n=24)$ & ACDF, laminoplasty & \\
\hline $\begin{array}{l}\text { Nagata et al., } \\
1996\end{array}$ & Retro & Japan & 173 & $\begin{array}{l}\text { Elderly } \geq 65 \text { yrs }(n=50) ; \text { nonelderly }<65 \text { yrs } \\
\quad(n=123)\end{array}$ & ACDF, laminoplasty & \\
\hline
\end{tabular}

$\mathrm{ACDF}$ = anterior cervical discectomy and fusion; NR = not reported; Pts = patients; retro = retrospective.

\section{Subgroup Analysis of Patients Older Than 75 Years}

Given variability of the operative definition of the elderly population in the included studies, we performed additional subgroup analysis focusing on an elderly population of at least 75 years old to further justify our aforementioned findings. A total of 7 studies used the exact cutoff value. Recovery rate was observed to be significant with mean difference of -11.9 ( -16.39 to $-7.37, \mathrm{p}<0.00001)$. The rate of each complication (i.e., C-5 palsy, CSF leak, pneumonia, and delirium) was not significantly different between elderly and nonelderly groups.

\section{Biases}

Publication bias was not significant as demonstrated in the funnel plot shown in Fig. 15.

\section{Discussion}

In the recent past, there have been several publications on adult deformity revealing successful and acceptable corrections in patients with lower morbidity. ${ }^{17,48}$ Surgeries for correcting cervical myelopathy in general take less operative time and have a narrower field of operation and 
TABLE 2. Baseline characteristics of elderly and nonelderly groups

\begin{tabular}{lcc}
\hline \multicolumn{1}{c}{ Variable } & $\begin{array}{c}\text { Elderly } \\
(\mathrm{n}=1169)\end{array}$ & $\begin{array}{c}\text { Nonelderly } \\
(\mathrm{n}=1699)\end{array}$ \\
\hline Mean age in yrs & $74.1 \pm 5.7$ & $54.6 \pm 10.0$ \\
\hline$\%$ male & 53.2 & 54.7 \\
\hline Mean no. of vertebral levels & $3.1 \pm 1.2$ & $4.2 \pm 1.2$ \\
\hline $\begin{array}{l}\text { \% posterior approach for surgical decom- } \\
\text { pression (laminoplasty or laminectomy) }\end{array}$ & 27.4 & 85.3 \\
\hline \% anterior approach (ACDF) & 72.6 & 14.7 \\
\hline$\%$ w/ diabetes & 55 & 45 \\
\hline
\end{tabular}

lower blood loss. However, there are several publications with the conclusion that the elderly population does not do well with surgeries for cervical myelopathy. Several significant advances in anesthesia have contributed to lesser morbidity in the elderly population. ${ }^{16}$ The aim of our study was to evaluate these papers for complications of surgery using detailed meta-analysis. Several papers reported the JOA score evaluation and we considered it in our scoring system.

Machino et al. in $2012^{21}$ analyzed 520 patients with cervical myelopathy, among whom 90 patients were older than 75 years. These patients underwent double-door laminoplasty after symptoms for 20 months. It was noted that elderly patients had a lower JOA score to begin with but recovered by 3 points away from the rest of the group. It is important to note that lower JOA scores were not solely reflective of myelopathy but also other comorbid conditions like arthritis, cerebrovascular disease, diabetes, and prostate hypertrophy. Recovery rate calculated using the
Hirabayashi scoring revealed no significant difference in rate of recovery between the groups. In addition, duration of surgery and mean blood loss were lower in the elderly population than in other groups. In 2015, Machino et al. ${ }^{22}$ performed laminoplasty in 118 patients older than 75 years of age and evaluated them based on JOA score, grip and release test, and 10-step test. Once again, elderly patients had lower JOA scores to begin with. Postoperatively, JOA score, grip and release test, and 10-step test scores were lower than those in the younger population, which can be attributed to a lower number of myelinated fibers in the elderly population. There were no significant differences in postoperative complications, blood loss, and operative time. All patients walked on postoperative Day 1 and on follow-up noted satisfactory recovery from surgery with good ambulation.

Nagashima et al. evaluated the outcomes from French window laminoplasty in 37 patients who were 80 years or older and compared them to a younger population. They noted no significant difference in complications and recovery rate but noted that progress of symptoms to significant deterioration was rather quick in older patients. The $40 \%$ recovery rate in the functional status among the $>80$-year population is lower than the younger group on JOA scoring but significant enough to improve their life style. ${ }^{32}$ Yoshida et al. evaluated 76 patients older than 75 years and noted that the expansive laminoplasty improved ambulation in the elderly population and reduced nursing care requirements based on JOA and FIM (functional independence measure) scoring. ${ }^{51}$

\section{Radiological Predictors}

Currently there is a general consensus among spine surgeons on MRI characteristics of multilevel T2 hyper-

\begin{tabular}{|c|c|c|c|c|c|c|c|c|c|c|c|}
\hline \multirow[b]{2}{*}{ Study or Subgroup } & \multicolumn{3}{|c|}{ Elderly } & \multicolumn{3}{|c|}{ Non-elderly } & \multirow{3}{*}{ Weight } & \multirow{2}{*}{$\begin{array}{l}\text { Mean Difference } \\
\text { IV, Random, } 95 \% \mathrm{CI}\end{array}$} & \multirow{2}{*}{\multicolumn{3}{|c|}{$\begin{array}{c}\text { Mean Difference } \\
\text { IV, Random, 95\% CI }\end{array}$}} \\
\hline & Mean & SD & Total & Mean & SD & Total & & & & & \\
\hline Kawaguchi, 2003 & 188 & 48 & 20 & 161 & 41 & 69 & & $27.00[3.85,50.15]$ & & & \\
\hline Machino, 2012 & 72 & 58.1 & 233 & 78 & 25 & 287 & $18.4 \%$ & $-6.00[-14.00,2.00]$ & & & \\
\hline Machino, 2015 & 74 & 20 & 304 & 79.8 & 25.6 & 201 & $19.4 \%$ & $-5.80[-9.99,-1.61]$ & & $=$ & \\
\hline Nakashima, 2015 & 183.8 & 79.5 & 119 & 176.2 & 8.5 & 360 & $15.8 \%$ & $7.60[-6.71,21.91]$ & & & \\
\hline Son, 2014 & 161 & 25 & 28 & 169 & 22 & 34 & $16.9 \%$ & $-8.00[-19.85,3.85]$ & & & \\
\hline Yoshida, 2013 & 64.6 & 36.7 & 76 & 103.6 & 49 & 293 & $17.6 \%$ & $-39.00[-48.98,-29.02]$ & & -- & \\
\hline Total $(95 \% \mathrm{CI})$ & & & 780 & & & 1244 & $100.0 \%$ & $-6.05[-18.65,6.54]$ & & & \\
\hline $\begin{array}{l}\text { Heterogeneity. Tau }{ }^{2}= \\
\text { Test for overall effect }\end{array}$ & $\begin{array}{l}207.97 \\
Z=0.9\end{array}$ & ; $\mathrm{Chi}^{2}$ & $\begin{array}{l}=51.71 \\
0.351\end{array}$ & $1 \mathrm{df}=$ & $2^{2}$ & 0.0000 & $1) ; 1^{2}=9$ & & $\frac{!}{-100}$ & $\begin{array}{l}-50 \\
\text { Favors elderly }\end{array}$ & Favors $n$ \\
\hline
\end{tabular}

FIG. 2. Forest plot showing the mean difference in operation time (mins) between elderly and nonelderly groups. IV = inverse variance.

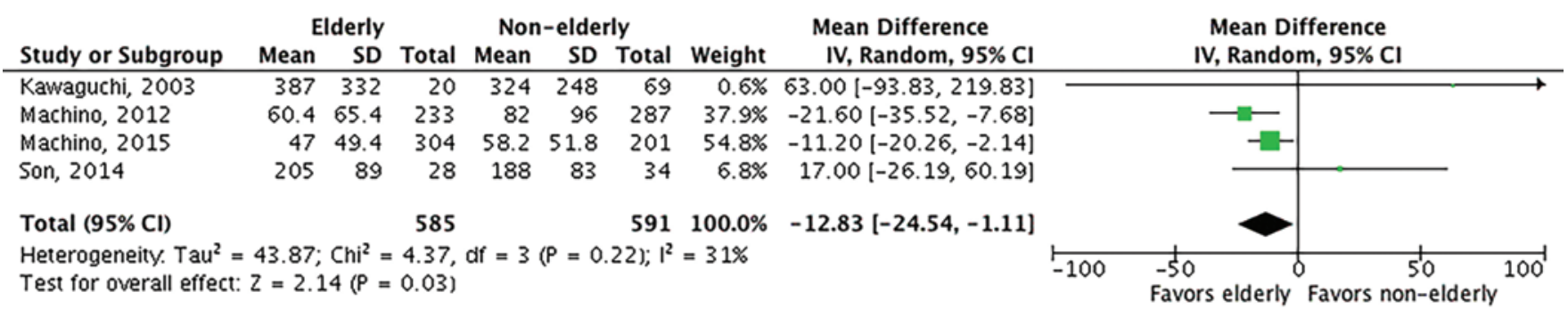

FIG. 3. Forest plot showing the mean difference in the volume of blood loss (ml) between elderly and nonelderly groups. 


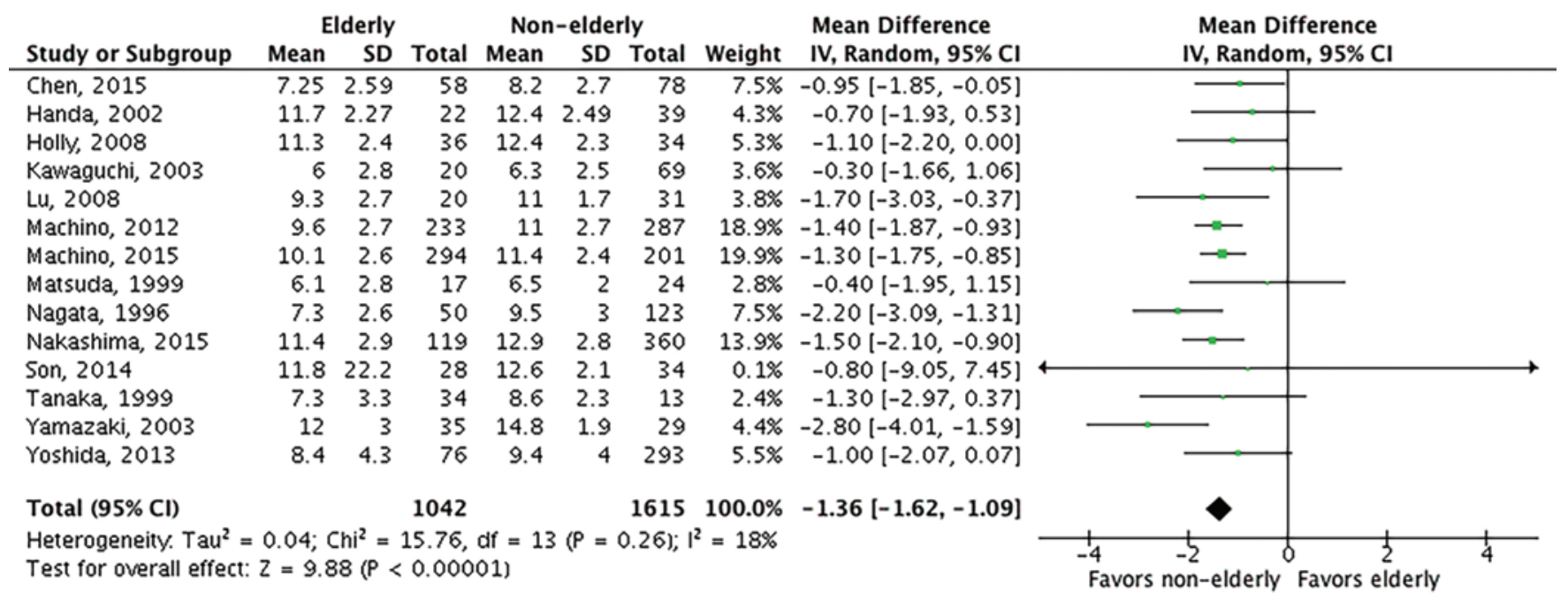

FIG. 4. Forest plot showing the mean difference of preoperative JOA score between elderly and nonelderly groups.

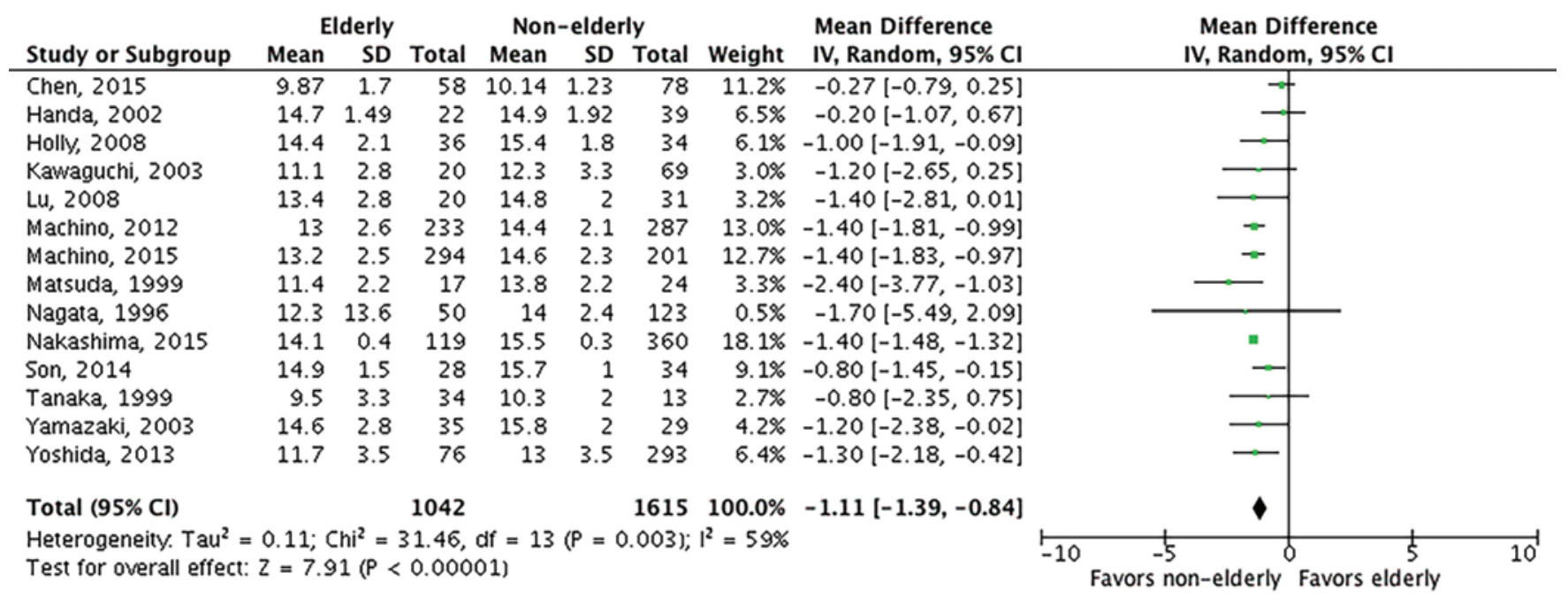

FIG. 5. Forest plot showing the mean difference of postoperative JOA score between elderly and nonelderly groups.

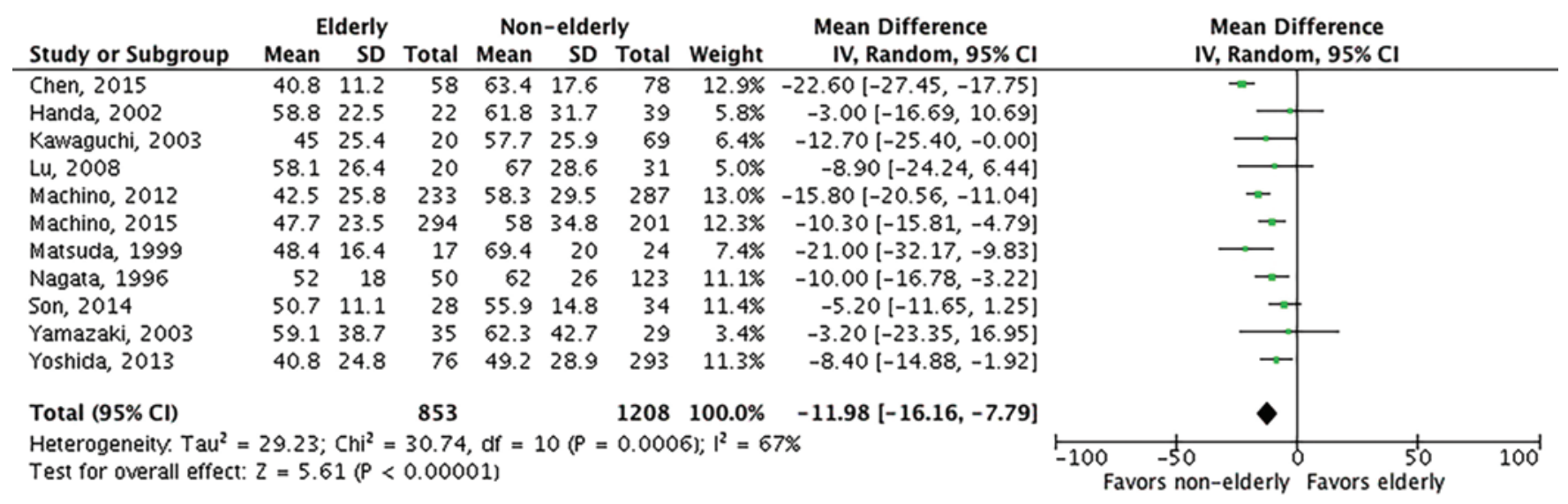

FIG. 6. Forest plot showing the mean difference in recovery rate (\%) between the elderly and nonelderly groups. Recovery rate is calculated using the same mentioned formula in each study. 


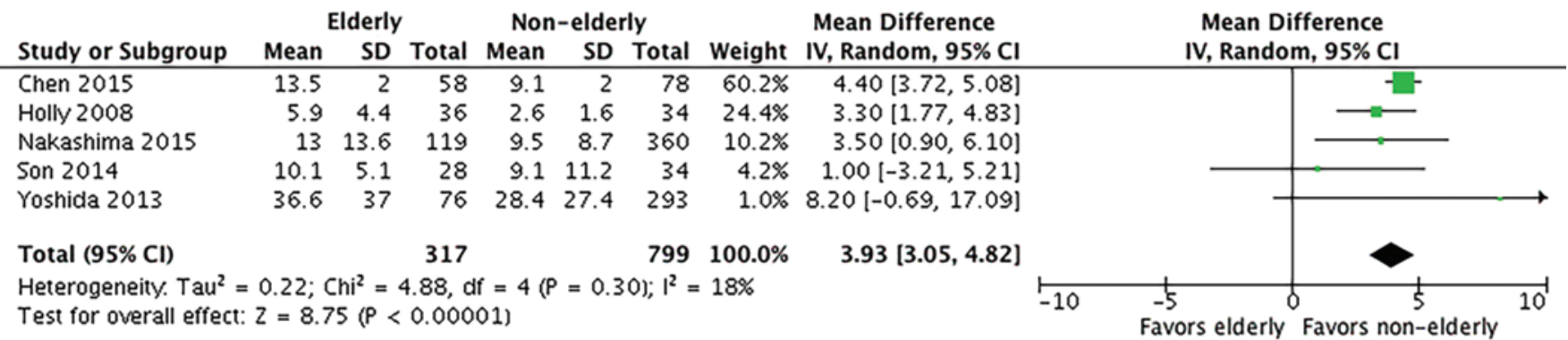

FIG. 7. Forest plot showing the mean difference in length of stay (days) between elderly and nonelderly groups.

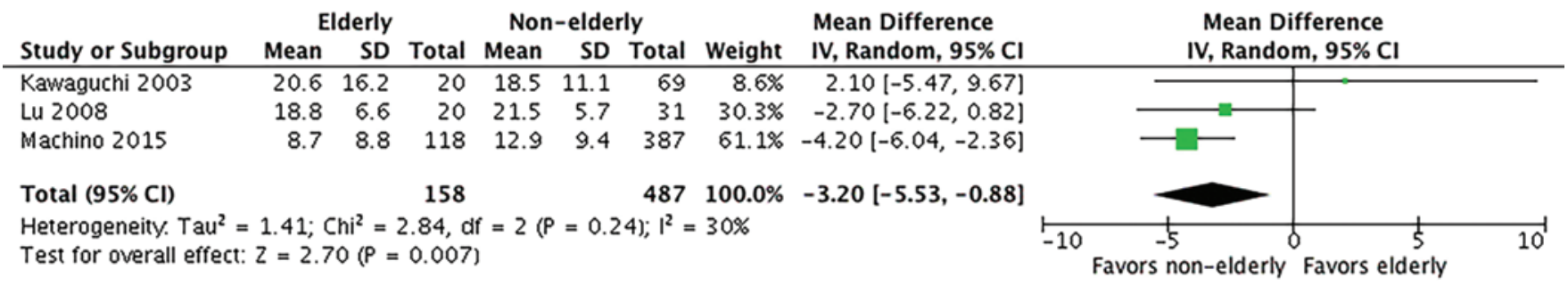

FIG. 8. Forest plot showing the mean difference of preoperative Cobb angle $\left(^{\circ}\right)$ between elderly and nonelderly groups.

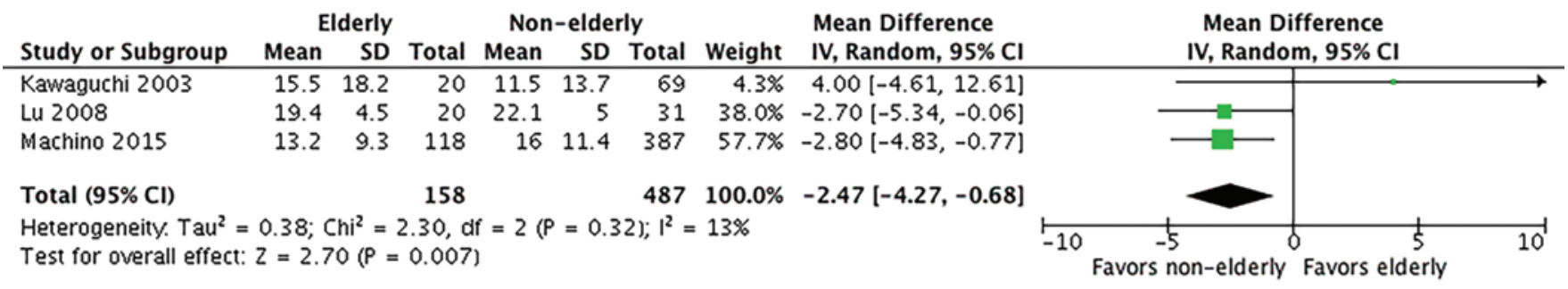

FIG. 9. Forest plot showing the mean difference of postoperative Cobb angle $\left({ }^{\circ}\right)$ between elderly and nonelderly groups.

\begin{tabular}{|c|c|c|c|c|c|c|c|c|c|c|c|}
\hline \multirow[b]{2}{*}{ Study or Subgroup } & \multicolumn{3}{|c|}{ Elderly } & \multicolumn{3}{|c|}{ Non-elderly } & \multirow{3}{*}{$\begin{array}{r}\text { Weight } \\
50.4 \%\end{array}$} & \multirow{3}{*}{$\begin{array}{c}\begin{array}{c}\text { Mean Difference } \\
\text { IV, Random, 95\% Cl }\end{array} \\
4.30[3.74,4.86]\end{array}$} & \multirow{2}{*}{\multicolumn{3}{|c|}{$\begin{array}{c}\text { Mean Difference } \\
\text { IV, Random, } 95 \% \mathrm{CI}\end{array}$}} \\
\hline & Mean & SD & Total & Mean & SD & Total & & & & & \\
\hline Kawaguchi 2003 & 17.8 & 1.1 & 20 & 13.5 & 1.2 & 69 & & & & 들 & \\
\hline Son 2014 & 20.4 & 2 & 28 & 20.1 & 1.6 & 34 & $49.6 \%$ & $0.30[-0.62,1.22]$ & & & \\
\hline Total $(95 \% \mathrm{Cl})$ & & & 48 & & & 103 & $100.0 \%$ & $2.32[-1.60,6.24]$ & & & \\
\hline $\begin{array}{l}\text { Heterogeneity. Tau }{ }^{2} \\
\text { Test for overall effec }\end{array}$ & $\begin{array}{l}7.85 \\
z=1.1\end{array}$ & $\begin{array}{l}\mathrm{hi}^{2}= \\
6(\mathrm{P}\end{array}$ & $\begin{aligned} & 53.42 \\
= & 0.25\end{aligned}$ & $\mathrm{df}=$ & $(P<)$ & 0.0000 & $1) ;\left.\right|^{2}=\subseteq$ & $38 \%$ & $\begin{array}{lr}-10 & -5 \\
& \text { Favors } \mathrm{n}\end{array}$ & & 10 \\
\hline
\end{tabular}

FIG. 10. Forest plot showing the postoperative canal diameter.

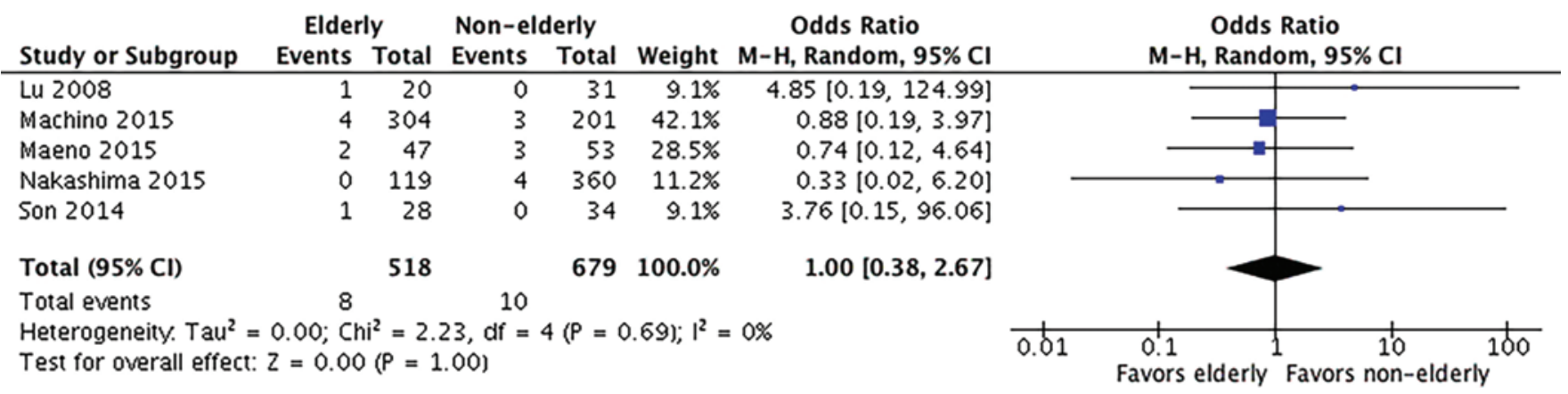

FIG. 11. Forest plot showing odds ratio of $\mathrm{C}-5$ palsy in the elderly group. $\mathrm{M}-\mathrm{H}=$ Mantel-Haenszel. 


\begin{tabular}{|c|c|c|c|c|c|c|c|c|c|}
\hline Study or Subgroup & \multicolumn{2}{|c|}{ Elderly } & \multicolumn{2}{|c|}{ Non-elderly } & Weight & $\begin{array}{c}\text { Odds Ratio } \\
\text { M-H, Random, } 95 \% \mathrm{Cl}\end{array}$ & \multicolumn{3}{|c|}{$\begin{array}{c}\text { Odds Ratio } \\
\mathrm{M}-\mathrm{H}, \text { Random, } 95 \% \mathrm{Cl}\end{array}$} \\
\hline Chen 2015 & 3 & 58 & 0 & 78 & $16.0 \%$ & $9.90[0.50,195.52]$ & & & \\
\hline Lu 2008 & 1 & 20 & 0 & 31 & $14.0 \%$ & $4.85[0.19,124.99]$ & & & \\
\hline Machino 2015 & 5 & 233 & 1 & 287 & $25.2 \%$ & $6.27[0.73,54.06]$ & & & \\
\hline Nakashima 2015 & 10 & 360 & 4 & 119 & $44.8 \%$ & $0.82[0.25,2.67]$ & & & \\
\hline Total $(95 \% \mathrm{Cl})$ & & 671 & & 515 & $100.0 \%$ & $2.62[0.67,10.27]$ & & & \\
\hline Total events & 19 & & 5 & & & & & & \\
\hline $\begin{array}{l}\text { Heterogeneity. Tau } \\
\text { Test for overall effect }\end{array}$ & $\begin{array}{l}0.72 ; \mathrm{Cr} \\
\mathrm{z}=1.38\end{array}$ & $\begin{array}{l}\mathrm{i}^{2}=4.7 \\
(P=0\end{array}$ & $\begin{array}{l}75, \mathrm{df}= \\
.17)\end{array}$ & $3(P=$ & $0.19) ; 1^{2}=$ & $=37 \%$ & 0.005 & $\begin{array}{c}0.1 \\
\text { Favors elderly }\end{array}$ & $\begin{array}{r}10 \\
\text { Favors non }\end{array}$ \\
\hline
\end{tabular}

FIG. 12. Forest plot showing the odds ratio of CSF leak in the elderly group.

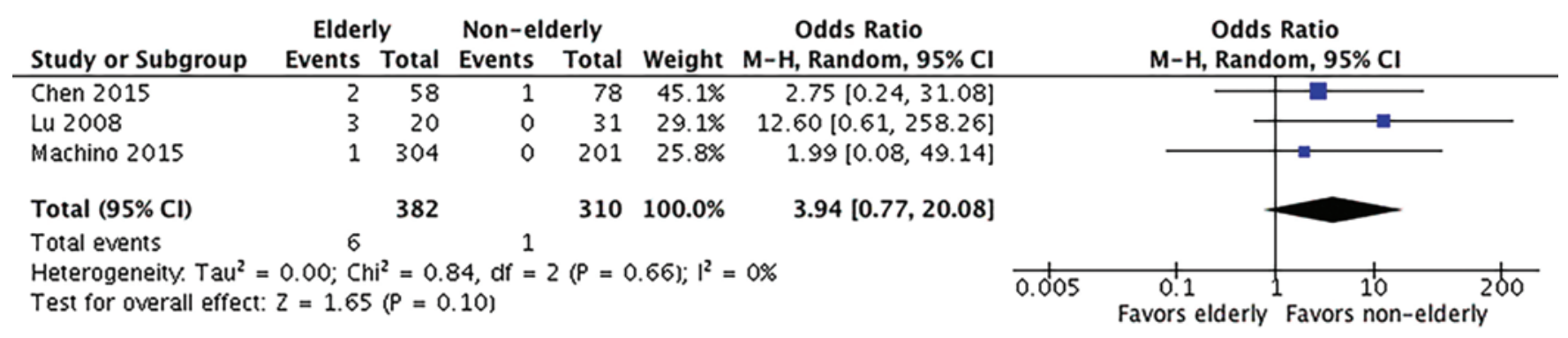

FIG. 13. Forest plot showing the odds ratio of pneumonia in the elderly group.

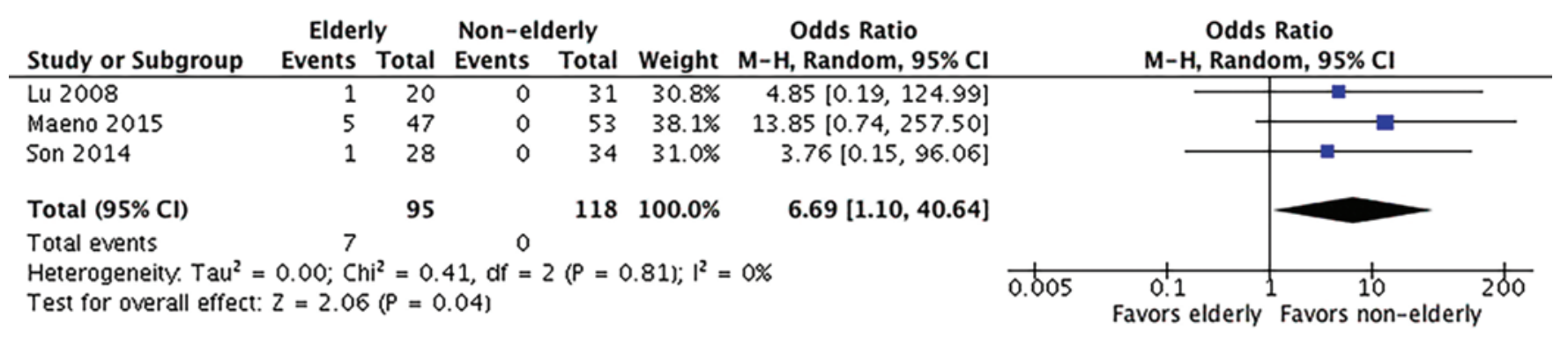

FIG. 14. Forest plot showing the odds ratio of delirium in the elderly group.

intensity, T1 focal hypointensity combined with T2 focal hyperintensity, and spinal cord atrophy, each indicating a need for surgical intervention. ${ }^{31}$ Recently, there has been increasing interest in measuring global spinal sagittal alignment as part of preoperative workup. It is widely believed that with global sagittal misalignment, decompression of the cervical canal alone may not yield a good outcome..$^{9,37,41}$ In certain scenarios, correction of thoracolumbar deformity may improve cervical spine alignment. ${ }^{4}$ However, Lee et al. demonstrated that laminoplasty led to increase in postoperative kyphosis but regional cervical sagittal balance did not correlate with outcome. ${ }^{19}$ On the other hand, Sakai et al. showed that a cutoff age of 75 years and $42 \mathrm{~mm}$ of the center gravity of the head to C-7 sagittal vertical axis (distance between anterior margin of external auditory canal plumb line and posterior-cranial corner of the C-7 vertebral body) were associated with postoperative kyphotic deformity. ${ }^{38}$ Smith et al. noted that the sagittal imbalance correlated directly with myelopathy symptoms and progression. ${ }^{40}$ Some evidence has suggested the addition of fusion if range of motion is more than $20^{\circ}$ as it has correlated with poorer outcomes due to postoperative kyphosis development in a group of elderly patients $(\mathrm{n}=$ 45) 60-86 years of age. ${ }^{24}$ It is apparent that existing sagittal plane deformity or regional cervical kyphosis leads to suboptimal outcome. Therefore, we suggest entire 36-inch spine images before offering surgery to elderly patients to prevent poorer outcome.

\section{Morbidity Following Surgery in the Elderly Group}

As mentioned above, postoperative delirium was the only complication found to be significant in our analysis. Shi et al., ${ }^{39}$ in their meta-analysis of patients who developed delirium following spine surgery, demonstrated age as the biggest risk factor ( $>70$ years old, OR 15.9, $\mathrm{p}<0.001$ ). Other significant factors included female sex, number of medications, and low preoperative hematocrit and albumin 


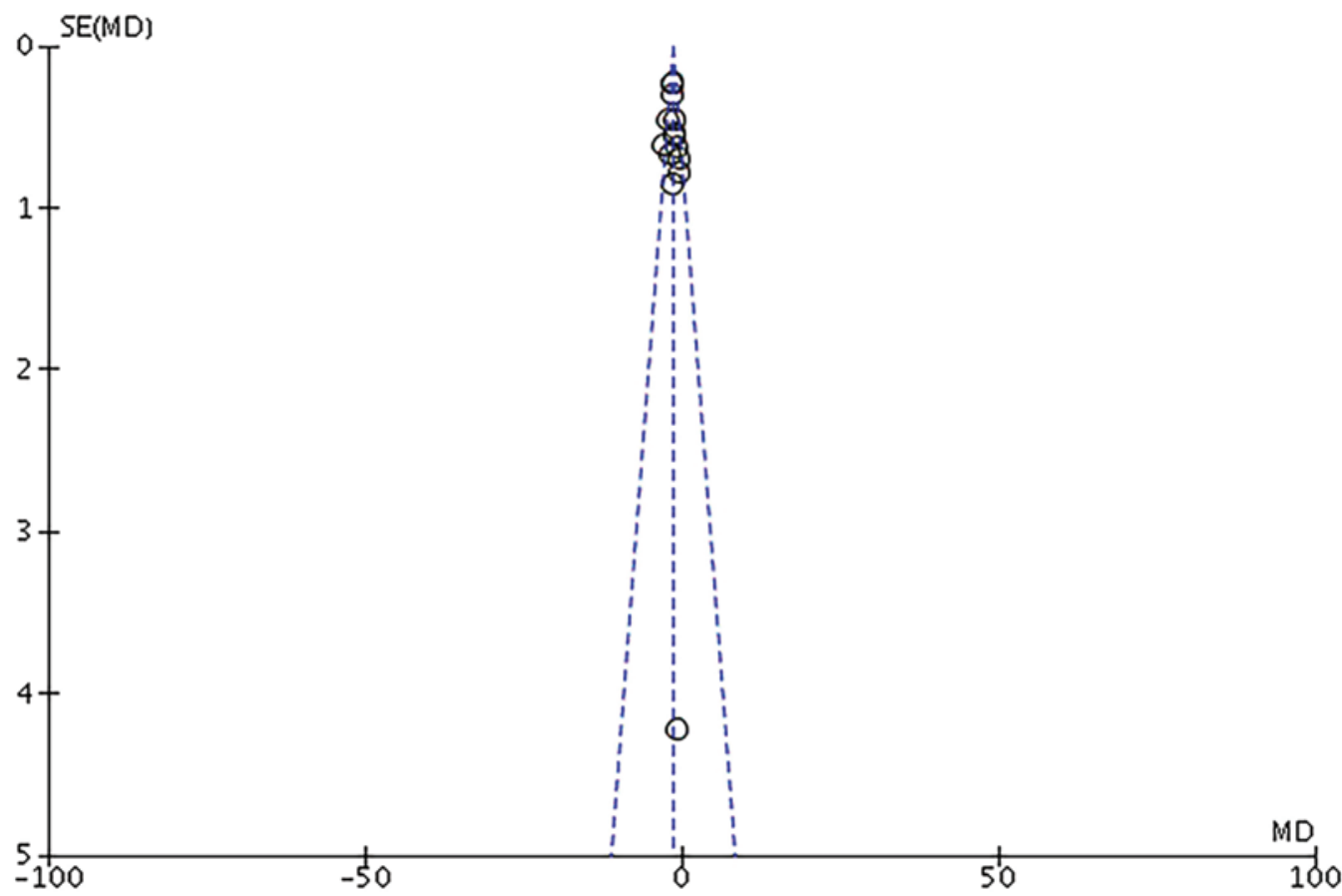

FIG. 15. Funnel plot showing publication bias was not significant.

levels. Nonetheless, the exact underlying pathophysiology of postoperative delirium among elderly patients remains unknown.

\section{Value of Surgical Treatment in Elderly: Is There a Significant Gain?}

In our analysis, we demonstrated lower recovery rate in the elderly patients. These patients do not seem to translate neurological recovery into functional improvements as well like their younger counterparts. Despite this observation, Nakashima et al. ${ }^{34}$ was the only group that looked into patient-reported outcome (Neck Disability Index and SF-36) and revealed no difference between the elderly and nonelderly cohorts. This implied that elderly patients can still make significant gains in their quality of life without the need to achieve as much improvement as their younger counterparts. Solely assessing the neurological improvement is insufficient to appreciate clinical outcome in the elderly population as sense of quality of life likely differs between age groups. Hence patients' experience in its totality should be prioritized in today's value-driven health care system.

In our institution we have been working closely with the anesthesiology team to limit perioperative fluid administration in the elderly. ${ }^{27-29} \mathrm{We}$ are in the process of implementing the "enhanced recovery after surgery" (ERAS) a protocol which begins from the preoperative conditioning until the patient is discharged. ${ }^{26,36}$ In addition, narcotic use is being replaced with administration of long acting bupivacaine. The data collection is in progress, and, to date, results still appear to be promising. We expect to publish these data in the near future.

\section{Limitations of the Study}

There exist numerous limitations in our study. As in many retrospective analyses, the limitations of the study include the lack of randomization. The outcomes were not blinded to investigators. There are different types of laminoplasty that were undertaken and some were combined with anterior cervical discectomy and fusion. For instance, in our study, we demonstrated lower intraoperative blood loss in the elderly. This observation may be due to the fact that the patients received smaller or less complex surgeries. Only one study, by Nakashima et al., ${ }^{34}$ used an adjustment model to control for potential confounders such as baseline severity score, smoking status, comorbidity score, diabetes, cardiovascular disease, and rheumatological disease. However, age remained the significant predictor for neurological recovery in the same study. The remaining included studies did not extend their investigation beyond univariate analysis. While it was a huge challenge to control these confounders, we provided a table showing baseline characteristics between younger and older patients. Nonetheless, we also performed subgroup analysis of the population older than 75 years in an attempt to minimize variability. In addition, there will always be a better outcome with surgeons who have performed several cervical decompression surgeries.

\section{Conclusions}

Cervical myelopathy is a morbid condition, and the elderly population is known to deteriorate rapidly with a lack of mobility and increased risk of being bedridden. We performed a meta-analysis on the outcomes of 2868 pa- 
tients and found that elderly patients started out with lower JOA scores and hence did not recover like their younger counterparts in the study. However, recovery reduced their dependence, as these patients required reduced nursing care. Furthermore, several publications have shown that recovery and complication rates are not significantly different in incidence from the younger population. We also suggest assessment of the entire spinal column for other deformities common in the elderly and that correction of these deformities can improve cervical alignment. Furthermore, coexisting deformities of the spine have led to limited recovery. By reducing operative time, blood loss, and perioperative fluid management, we can reduce complications and improve recovery rate. ${ }^{3}$

\section{References}

1. Chen J, Liu Z, Zhong G, Qian L, Li Z, Chen B, et al: Surgical treatment for cervical spondylotic myelopathy in elderly patients: a retrospective study. Clin Neurol Neurosurg 132:47-51, 2015

2. Emery SE: Cervical spondylotic myelopathy: diagnosis and treatment. J Am Acad Orthop Surg 9:376-388, 2001

3. Feng F, Ruan W, Liu Z, Li Y, Cai L: Anterior versus posterior approach for the treatment of cervical compressive myelopathy due to ossification of the posterior longitudinal ligament: A systematic review and meta-analysis. Int J Surg 27:26-33, 2016

4. Ha Y, Schwab F, Lafage V, Mundis G, Shaffrey C, Smith J, et al: Reciprocal changes in cervical spine alignment after corrective thoracolumbar deformity surgery. Eur Spine J 23:552-559, 2014

5. Handa Y, Kubota T, Ishii H, Sato K, Tsuchida A, Arai Y: Evaluation of prognostic factors and clinical outcome in elderly patients in whom expansive laminoplasty is performed for cervical myelopathy due to multisegmental spondylotic canal stenosis. A retrospective comparison with younger patients. J Neurosurg 96 (2 Suppl):173-179, 2002

6. Hayashi H, Okada K, Hashimoto J, Tada K, Ueno R: Cervical spondylotic myelopathy in the aged patient. A radiographic evaluation of the aging changes in the cervical spine and etiologic factors of myelopathy. Spine (Phila Pa 1976) 13:618625, 1988

7. Holly LT, Moftakhar P, Khoo LT, Shamie AN, Wang JC: Surgical outcomes of elderly patients with cervical spondylotic myelopathy. Surg Neurol 69:233-240, 2008

8. Ishii M, Wada E, Ishii T, Kawai H, Kaneko N, Fuji T: Laminoplasty for patients aged 75 years or older with cervical myelopathy. J Orthop Surg (Hong Kong) 16:211-214, 2008

9. Iyer S, Nemani VM, Nguyen J, Elysee J, Burapachaisri A, Ames CP, et al: The impact of cervical sagittal alignment parameters on neck disability. Spine (Phila Pa 1976) 41:371377,2016

10. Kalsi-Ryan S, Karadimas SK, Fehlings MG: Cervical spondylotic myelopathy: the clinical phenomenon and the current pathobiology of an increasingly prevalent and devastating disorder. Neuroscientist 19:409-421, 2013

11. Kanchiku T, Imajo Y, Suzuki H, Yoshida Y, Nishida N, Taguchi T: Results of surgical treatment of cervical spondylotic myelopathy in patients aged 75 years or more: a comparative study of operative methods. Arch Orthop Trauma Surg 134:1045-1050, 2014

12. Kawaguchi Y, Kanamori M, Ishihara H, Ohmori K, Abe Y, Kimura T: Pathomechanism of myelopathy and surgical results of laminoplasty in elderly patients with cervical spondylosis. Spine (Phila Pa 1976) 28:2209-2214, 2003

13. Kellgren JH, Lawrence JS: Osteo-arthrosis and disk degeneration in an urban population. Ann Rheum Dis 17:388-397, 1958
14. Kimura J: F-wave velocity in the central segment of the median and ulnar nerves. A study in normal subjects and in patients with Charcot-Marie-Tooth disease. Neurology 24:539-546, 1974

15. Klineberg E: Cervical spondylotic myelopathy: a review of the evidence. Orthop Clin North Am 41:193-202, 2010

16. Koga FA, El Dib R, Wakasugui W, Roça CT, Corrente JE, Braz MG, et al: Anesthesia-related and perioperative cardiac arrest in low- and high-income countries: a systematic review with meta-regression and proportional meta-analysis. Medicine (Baltimore) 94:e1465, 2015

17. Lau D, Funao H, Clark AJ, Nicholls F, Smith J, Bess S, et al: The clinical correlation of the Hart-ISSG proximal junctional kyphosis severity scale with health related quality of life outcomes and need for revision surgery. Spine (Phila Pa 1976) 41:213-223, 2016

18. Lawrence JS: Disc degeneration. Its frequency and relationship to symptoms. Ann Rheum Dis 28:121-138, 1969

19. Lee CK, Shin DA, Yi S, Kim KN, Shin HC, Yoon H, et al: Correlation between cervical spine sagittal alignment and clinical outcome after cervical laminoplasty for ossification of the posterior longitudinal ligament. J Neurosurg Spine 24:100-107, 2016

20. Lu J, Wu X, Li Y, Kong X: Surgical results of anterior corpectomy in the aged patients with cervical myelopathy. Eur Spine J 17:129-135, 2008

21. Machino M, Yukawa Y, Hida T, Ito K, Nakashima H, Kanbara S, et al: Can elderly patients recover adequately after laminoplasty?: a comparative study of 520 patients with cervical spondylotic myelopathy. Spine (Phila Pa 1976) 37:667-671, 2012

22. Machino M, Yukawa Y, Imagama S, Ito K, Katayama Y, Matsumoto T, et al: Surgical treatment assessment of cervical laminoplasty using quantitative performance evaluation in elderly patients: a prospective comparative study in 505 patients with cervical spondylotic myelopathy. Spine (Phila Pa 1976) 41:757-763, 2016

23. Maeno T, Okuda S, Yamashita T, Matsumoto T, Yamasaki R, Oda T, et al: Age-related surgical outcomes of laminoplasty for cervical spondylotic myelopathy. Global Spine J 5:118123,2015

24. Maruo K, Moriyama T, Tachibana T, Inoue S, Arizumi F, Daimon T, et al: The impact of dynamic factors on surgical outcomes after double-door laminoplasty for ossification of the posterior longitudinal ligament of the cervical spine. $\mathbf{J}$ Neurosurg Spine 21:938-943, 2014

25. Matsuda Y, Shibata T, Oki S, Kawatani Y, Mashima N, Oishi $\mathrm{H}$ : Outcomes of surgical treatment for cervical myelopathy in patients more than 75 years of age. Spine (Phila Pa 1976) 24:529-534, 1999

26. McDonald R: Enhanced recovery clinical education programme improves quality of post-operative care. BMJ Qual Improv Rep 4:u208370.w3387, 2015

27. Merchant RN, Davies JM: Fluid management issues in Enhanced Recovery After Surgery and Canadian Anesthesiologists' Society standards. Can J Anaesth 62:930, 2015 (Letter)

28. Miller TE, Roche AM, Mythen M: Fluid management and goal-directed therapy as an adjunct to Enhanced Recovery After Surgery (ERAS). Can J Anaesth 62:158-168, 2015

29. Miller TE, Roche AM, Mythen M: In reply: Fluid management issues in Enhanced Recovery After Surgery and Canadian Anesthesiologists' Society standards. Can J Anaesth 62:931, 2015 (Letter)

30. Moore AP, Blumhardt LD: A prospective survey of the causes of non-traumatic spastic paraparesis and tetraparesis in 585 patients. Spinal Cord 35:361-367, 1997

31. Mummaneni PV, Kaiser MG, Matz PG, Anderson PA, Groff M, Heary R, et al: Preoperative patient selection with mag- 
netic resonance imaging, computed tomography, and electroencephalography: does the test predict outcome after cervical surgery? J Neurosurg Spine 11:119-129, 2009

32. Nagashima H, Dokai T, Hashiguchi H, Ishii H, Kameyama Y, Katae Y, et al: Clinical features and surgical outcomes of cervical spondylotic myelopathy in patients aged 80 years or older: a multi-center retrospective study. Eur Spine J 20:240-246, 2011

33. Nagata K, Ohashi T, Abe J, Morita M, Inoue A: Cervical myelopathy in elderly patients: clinical results and MRI findings before and after decompression surgery. Spinal Cord 34:220-226, 1996

34. Nakashima H, Tetreault LA, Nagoshi N, Nouri A, Kopjar B, Arnold PM, et al: Does age affect surgical outcomes in patients with degenerative cervical myelopathy? Results from the prospective multicenter AOSpine International study on 479 patients. J Neurol Neurosurg Psychiatry [epub ahead of print], 2015

35. Ortman JM, Velkoff VA, Hogan H: An Aging Nation: The Older Population in the United States; Population Estimates and Projections. Washington, DC: US Census Bureau, 2014 (https://www.census.gov/prod/2014pubs/p25-1140. pdf) [Accessed April 5, 2016]

36. Pędziwiatr M, Pisarska M, Wierdak M, Major P, Rubinkiewicz M, Kisielewski M, et al: The use of the Enhanced Recovery After Surgery (ERAS) protocol in patients undergoing laparoscopic surgery for colorectal cancer-a comparative analysis of patients aged above 80 and below 55. Pol Przegl Chir 87:565-572, 2015

37. Ramchandran S, Smith JS, Ailon T, Klineberg E, Shaffrey C, Lafage V, et al: Assessment of impact of long-cassette standing X-rays on surgical planning for cervical pathology: an international survey of spine surgeons. Neurosurgery 78:717-724, 2016

38. Sakai K, Yoshii T, Hirai T, Arai Y, Torigoe I, Tomori M, et al: Cervical sagittal imbalance is a predictor of kyphotic deformity after laminoplasty in cervical spondylotic myelopathy patients without preoperative kyphotic alignment. Spine (Phila Pa 1976) 41:299-305, 2016

39. Shi C, Yang C, Gao R, Yuan W: Risk factors for delirium after spinal surgery: a meta-analysis. World Neurosurg 84:1466-1472, 2015

40. Smith JS, Lafage V, Ryan DJ, Shaffrey CI, Schwab FJ, Patel AA, et al: Association of myelopathy scores with cervical sagittal balance and normalized spinal cord volume: analysis of 56 preoperative cases from the AOSpine North America Myelopathy study. Spine (Phila Pa 1976) 38 (22 Suppl 1):S161-S170, 2013

41. Smith JS, Ramchandran S, Lafage V, Shaffrey CI, Ailon T, Klineberg E, et al: Prospective multicenter assessment of early complication rates associated with adult cervical deformity surgery in 78 patients. Neurosurgery [epub ahead of print], 2015

42. Son DK, Son DW, Song GS, Lee SW: Effectiveness of the laminoplasty in the elderly patients with cervical spondylotic myelopathy. Korean J Spine 11:39-44, 2014

43. Tanaka J, Seki N, Tokimura F, Doi K, Inoue S: Operative results of canal-expansive laminoplasty for cervical spondylotic myelopathy in elderly patients. Spine (Phila Pa 1976) 24:2308-2312, 1999

44. Tepe HJ: [Frequency of osteochondrotic roentgen findings in the cervical spine of 400 adults being free of symptoms.] Fortschr Geb Rontgenstr Nuklearmed 85:659-663, 1956 (Ger)

45. Toledano M, Bartleson JD: Cervical spondylotic myelopathy. Neurol Clin 31:287-305, 2013

46. Tracy JA, Bartleson JD: Cervical spondylotic myelopathy. Neurologist 16:176-187, 2010

47. van Tulder M, Furlan A, Bombardier C, Bouter L: Updated method guidelines for systematic reviews in the Cochrane collaboration back review group. Spine (Phila Pa 1976) 28:1290-1299, 2003

48. Wang MY, Madhavan K: Mini-open pedicle subtraction osteotomy: surgical technique. World Neurosurg 81:843. e11-843.e14, 2014

49. Wang MY, Widi G, Levi AD: The safety profile of lumbar spinal surgery in elderly patients 85 years and older. Neurosurg Focus 39(4):E3, 2015

50. Yamazaki T, Yanaka K, Sato H, Uemura K, Tsukada A, Nose T: Cervical spondylotic myelopathy: surgical results and factors affecting outcome with special reference to age differences. Neurosurgery 52:122-126, 2003

51. Yoshida G, Kanemura T, Ishikawa Y, Matsumoto A, Ito $Z$, Tauchi R, et al: The effects of surgery on locomotion in elderly patients with cervical spondylotic myelopathy. Eur Spine J 22:2545-2551, 2013

52. Young WF: Cervical spondylotic myelopathy: a common cause of spinal cord dysfunction in older persons. Am Fam Physician 62:1064-1070, 1073, 2000

\section{Disclosures}

Dr. Wang reports that he is a consultant for DePuy Spine, JoiMax, Aesculap Spine, and K2M; a patent holder with DePuy Spine; has direct stock ownership in ISD; and received support of non-study-related clinical or research effort from the Department of Defense.

\section{Author Contributions}

Conception and design: Madhavan, Wang. Acquisition of data: Chieng, Foong. Analysis and interpretation of data: Madhavan, Chieng, Foong. Drafting the article: Madhavan, Chieng. Critically revising the article: Madhavan, Wang. Approved the final version of the manuscript on behalf of all authors: Madhavan. Statistical analysis: Chieng. Administrative/technical/material support: Wang. Study supervision: Wang.

\section{Correspondence}

Karthik Madhavan, Department of Neurological Surgery, University of Miami Miller School of Medicine, Lois Pope LIFE Center, 2nd Fl., 1095 NW 14th Terrace, Miami, FL 33136. email: drkarthik19@gmail.com. 